\title{
Vibrio cholerae non-01 - the first reported case of keratitis in a healthy patient
}

Wei-Dar Chen', Li-Ju Lai ${ }^{1,2}$, Wei-Hsiu Hsur, ${ }^{2,3}$ and Tsung-Yu Huang ${ }^{4,5^{*}}$ (D)

\begin{abstract}
Background: Vibrio cholerae non-O1 is a virulent pathogen that causes significant morbidity and mortality in humans. Herein, we report a case of corneal ulcer caused by this pathogen.

Case presentation: A 59-year-old fisherman with no systemic history was struck in the right eye by a marine shrimp and developed keratitis. Corneal scrapping culture revealed the presence of the V. cholerae non-O1, and its identification was confirmed by Analytical Profile Index 20E system and polymerase chain reaction. He was successfully treated with topical levofloxacin (0.3\%) and fortified amikacin $(12.5 \mathrm{mg} / \mathrm{mL})$ for 2 weeks. The visual acuity recovered to 20/25 after treatment without complications.

Conclusions: This is the first case report of keratitis caused by V. cholerae non-O1 strain. Ocular injury by marine creatures and contaminated seawater can contribute to severe corneal ulcer. Early diagnosis can be achieved by meticulous history taking and a comprehensive laboratory workup. Simultaneously, an effective antibiotic therapy can lead to a positive outcome.
\end{abstract}

Keywords: Vibrio cholerae non-O1, Keratitis, Virulence factor, Marine shrimp, Corneal ulcer

\section{Introduction}

Vibrio cholerae is a facultative anaerobic gram-negative comma-shaped bacillus that exists ubiquitously in marine and estuarine environments. Exposure to contaminated water and ingestion of raw seafood are crucial routes of infection that causes overwhelming morbidity and mortality in humans [1]. V. cholerae serogroup O1 and $\mathrm{O} 139$ primarily contribute to pandemic Vibrio gastroenteritis by means of cardinal virulence factors of cholera toxin (CT) and toxin-coregulated pilus (TCP). Similarly, non-cholera Vibrio including Vibrio parahaemolyticus and Vibrio vulnificus (V. vulnificus) can lead to cholera-like diarrhea, open wound infection, necrotizing fasciitis and septicemia via multiple virulence determinants such as capsular polysaccharide, hemolysin, siderophores and metalloproteases [2, 3]. These major pathological Vibrio species have been extensively studied for their detrimental effect on public health. However,

\footnotetext{
* Correspondence: r12045@cgmh.org.tw

${ }^{4}$ Division of Infectious Diseases, Department of Internal Medicine, Chang Gung Memorial Hospital, Chiayi, Taiwan

${ }^{5}$ Graduate Institute of Clinical Medical Sciences, College of Medicine, Chang Gung University, Taoyuan, Taiwan

Full list of author information is available at the end of the article
}

pestilent $V$. cholerae non-O1/ non-O139 infection has gained attention over the past decade. A few studies have reported cases of extra-intestinal Vibrio infections caused by $V$. cholerae non-O1/non-O139 stains, including soft tissue infection, pneumonia, acute cholecystitis, liver abscess, peritonitis, urinary tract infection, septicemia and meningitis in addition to acute enteric illness $[4,5]$. Nevertheless, the incidence of ocular infection caused by $V$. cholerae non-O1/non-O139 was rather low. Only one case of endophthalmitis attributed to $V$. cholerae non-O1/non-O139 strain in a cirrhotic patient with septicemia has been reported [6]. Herein, we reported a case of a healthy patient with $V$. cholerae non$\mathrm{O} 1$ keratitis and searched the related literature to discuss pathogenesis, diagnosis and management of $V$. cholerae keratitis.

\section{Case presentation}

A 59-year-old healthy fisherman presented with right eye pain, redness, tearing and photophobia for 1 day and the symptoms persisted. According to his statement, his right eye was struck by a marine shrimp while fishing. The patient denied a history of major systemic diseases such as diabetes, hypertension, or liver cirrhosis. The 


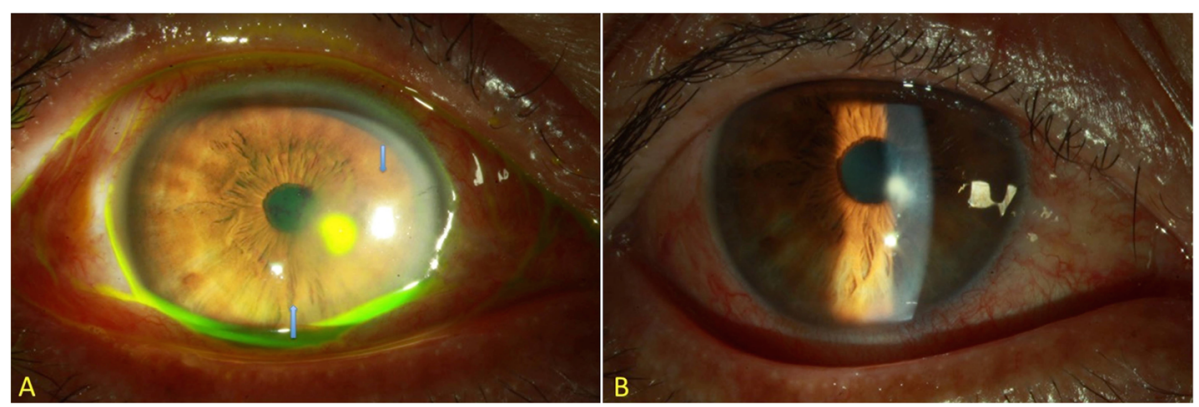

Fig. 1 Vibrio cholerae (V. cholerae) non-O1 keratitis. a. Cornea epithelial defect $\left(1.3 \times 1.8 \mathrm{~mm}^{2}\right)$ with dense stromal infiltration on the center cornea. Cornea edema with Descemet membrane folding was also found $\left(5.0 \times 5.6 \mathrm{~mm}^{2}\right)$. Arrows indicated the area of cornea edema. b Small cornea opacity without epithelial defect was noted 1 week after treatment

best-corrected visual acuity was $20 / 60$ in the right eye and $20 / 20$ in the left eye. Slit-lamp examination showed moderate conjunctival injection with slight chemosis, and a central stromal infiltration of approximately $1.3 \times$ $1.8 \mathrm{~mm}^{2}$. Simultaneously, corneal edema with Descemet membrane folding around the lesion was also observed (Fig. 1a). There was no sign of anterior chamber inflammation or endophthalmitis. Initially, under the suspicion of bacterial or fungal infection, the patient was empirically treated with hourly Cravit (levofloxacin oph. Soln, $0.5 \%$, Santen, Japan) and fortified amphotericin B (1 mg/ $\mathrm{mL})$. Two days later, right eye pain improved slightly. The gram staining of the corneal culture showed Vibrio $s p$., and the yellow colony in thiosulfate-citrate-bile saltssucrose (TBCS) agar was highly identified as $V$. cholerae. Moreover, the negative result in the agglutination test confirmed the non-O1 strain (Fig. 2a-c). Thereafter, the identity of the $V$. cholerae was reconfirmed by laboratory analysis with Analytical Profile Index 20E (API 20E) (Fig. 2d) and polymerase chain reaction (PCR) (Fig. 3). Following the identification of $V$. cholerae non-O1, we halted the use of amphotericin B. Meanwhile, antimicrobial minimal inhibitory concentration testing was performed for this pathogen (Table 1). Based on the results of the test, the antibiotic regimen was changed to topical amikacin $(12.5 \mathrm{mg} / \mathrm{mL})$ and Cravit four times daily. One week later, the right uncorrected visual acuity rapidly recovered to 20/25 and corneal infiltration improved (Fig. 1b). The frequency of treatment was tapered gradually without any complication.

\section{Discussion and conclusions}

This is the first case of infectious keratitis caused by $V$. cholerae non-O1. Prior to our case, the first published case of ocular infection with $V$. cholerae non-O1 was an endophthalmitis in a cirrhotic patient with septicemia [6]. Corneal pathogenesis of the $V$. cholerae non-O1 strain has not been clearly elucidated yet due to its rare occurrence in ocular tissue. $V$. cholerae non-O1 can potentially bring on pandemic gastroenteritis and extraintestinal diseases without using lethal virulence factors such as CT and TCP. Some studies have indicated that

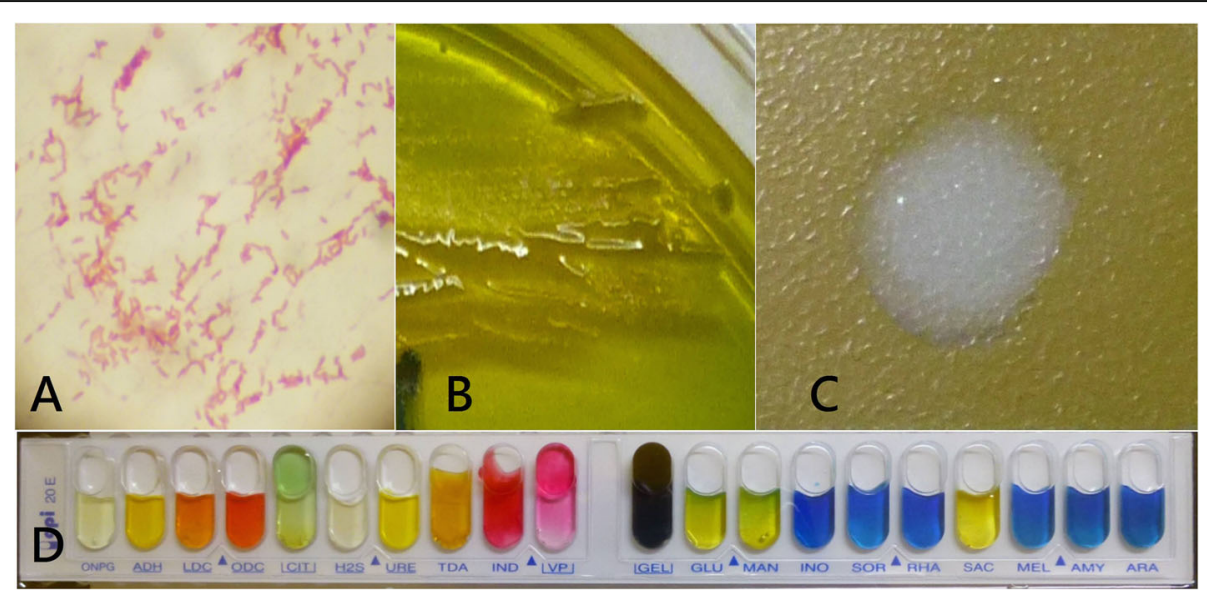

Fig. 2 Colonies of V. cholerae non-O1 (a). Gram stain (b). Thiosulfate citrate bile salts sucrose (TCBS) agar (c). Negative agglutination test (d). The result of Analytical Profile Index 20E (API 20E) Biochemical Test Strip 


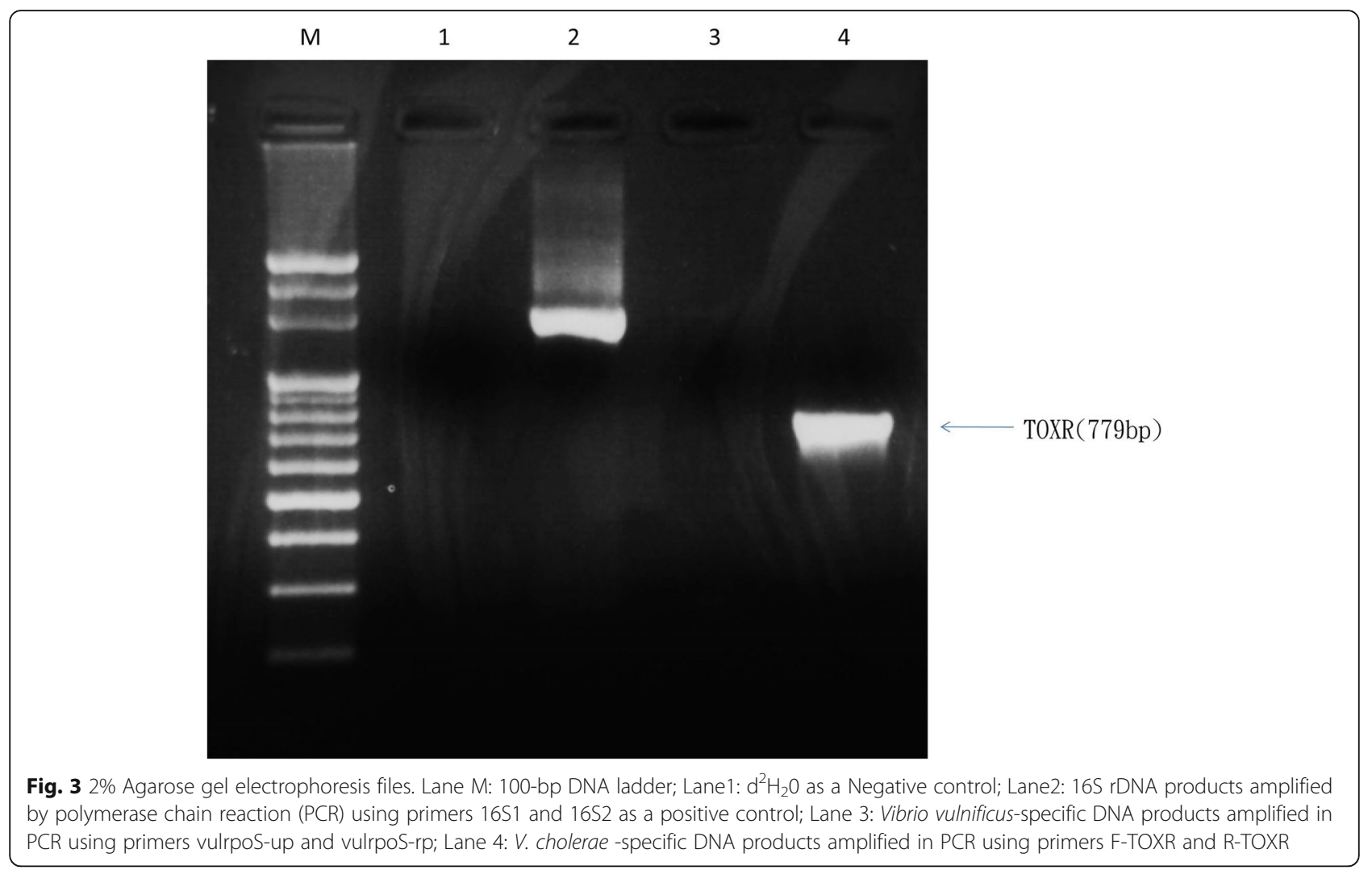

$V$. cholerae non-O1 possess unique characteristics to evade immune surveillance and destroy its target precisely $[7,8]$.

Hemolysin, hemagglutinin protease, repeats in toxin (RXT) and type VI secretion system (T6SS) are crucial virulence factors of $V$. cholerae non-O1 [7]. $V$. cholerae

Table 1 Susceptibilities of the clinical isolate of $V$. cholerae non01 to 14 antimicrobial agents

\begin{tabular}{ll}
\hline Antimicrobial agent & MIC $(\mathrm{ug} / \mathrm{ml})$ \\
\hline Amikacin & 4 \\
Gentamicin & 0.5 \\
Tetracycline & 1 \\
Tigecycline & 0.25 \\
Ciprofloxacin & 0.023 \\
Ertapenem & 0.023 \\
Imipenem & 0.75 \\
Meropenem & 0.19 \\
Ceftazidime & 0.094 \\
Ceftriaxone & 0.016 \\
Cefuroxime & 0.125 \\
Ampicillin & 1.5 \\
Ampicillin-sulbactam & 1 \\
Aztreonam & 0.38
\end{tabular}

MIC Minimum Inhibitory Concentration
non-O1 activates the vacuolating process regulated by hemolysin protein to interfere with intracellular homeostasis and ion exchange, and subsequently impels cellular cytolysis [9]. Therefore, hemolysin-induced vacuolation can potentially disrupt corneal epithelial and endothelial cells to trigger cell damage. Furthermore, occludin and zonula occludens-1 (ZO-1) are enriched in the corneal epithelium as first-line defense components [10]. In $V$. cholerae non-O1, hemagglutinin protease, encoded by the hap gene, can degrade essential tight junction-associated protein occludin and disrupt $\mathrm{ZO}-1$ conformation [11]. It is reasonable to infer that $V$. cholerae non-O1 can directly destroy the epithelial occludin and $\mathrm{ZO}-1$ via hemagglutinin protease, digest collagens and abolish corneal transparency. In addition, RTX, akin to exotoxin of $V$. cholerae, was found to be involved in the detachment and round-up of epithelial cells [12]. $V$. cholerae non-O1 can break down corneal epithelium and stroma using the distinctive cytotoxic property of the RTX. T6SS, found in gram-negative bacteria such as Pseudomonas aeruginosa and Escherichia coli, is a cellpuncturing device that translocates effector proteins into eukaryotic host cells [13]. P. aeruginosa has been shown to invades cornea with the assistance of T6SS [14], Hence, it is possible for $V$. cholerae non-O1 to adopt a similar strategy to cause keratitis. These presumptions require further microbiological research and laboratory 
analysis to determine the pathogenesis of the $V$. cholerae non-O1 keratitis.

In the present case, we initially doubted the presence of this pathogenic strain in the corneal culture because $V$. cholerae has never been reported in keratitis. Hence, it is necessary to validate this pathogen using advanced laboratory methods. The API 20E microtest and real-time PCR are suitable choices. The API 20E is an efficient biochemical kit to discriminate members of gram-negative bacilli in $24 \mathrm{~h}$. Furthermore, the API 20E has a higher detection rate for $V$. cholerae than analogous biochemical panels [15]. On the other hand, real-time PCR enables the most accurate molecular identification for $V$. cholera and is faster than the API 20E detection [16]. Target genes including hlyA, tcpI, toxR and ompU are available for the screening of $V$. choerae serotypes [17]. Both of methods are recommended for the diagnosis of intractable infectious ophthalmic due to their advantages of a short reaction time and enhanced accuracy of detection.

$V$. cholerae non-O1 is assumed to be an opportunistic pathogen, although it occasionally causes severe illness
[5]. Hence, efficient treatment for $V$. cholerae non-O1 infection has not been determined yet, particularly in ocular diseases. Yang et al. reported the first case of $V$. cholerae non-O1/non-O139 endophthalmitis following septicemia in a cirrhotic patient [6]. This patient received an intravitreal injection of vancomycin and ceftazidime, and a systemic intravenous injection of ceftriaxone $(2 \mathrm{~g}, \mathrm{q} 12 \mathrm{~h})$. Eventually, the patient died of sepsis and respiratory failure. Moreover, sporadic medical regimens for $V$. vulnificus keratitis were delineated. DiGaetano et al. (1989) combined medical treatment and surgical debridement for two cases of $V$. vulnificus keratitis [18]. Massey et al. (2000) used topical therapy with ciprofloxacin and fortified vancomycin for one case of $V$. vulnificus keratitis [19]. Penland et al. (2000) demonstrated that topical application of ciprofloxacin and cefazolin can treat the $V$. vulnificus keratitis [2]. You et al. (2008) used surgical debridement and systemic antibiotics (oral and intravenous injection) for $V$. vulnificus keratitis [20]. Despite the availability of prior case reports (Table 2), therapeutic options for ocular $V$.

Table 2 Reported cases of Vibrio spp. Keratitis

\begin{tabular}{|c|c|c|c|c|}
\hline Case & Reference & Species & Risk factor & Treatment \\
\hline 1 & DiGaetano et al. [18] 1989 & V. vulnificus & Shucking oysters & $\begin{array}{l}\text { Topical: } \\
\text { Gentamycin }(9.1 \mathrm{mg} / \mathrm{mL}) \\
\text { Maxitrol }^{\mathrm{a}} \\
\text { Cefazloin }(33 \mathrm{mg} / \mathrm{mL}) \\
\text { Surgical debridement (day 21) }\end{array}$ \\
\hline 2 & DiGaetano et al. [18] 1989 & V. vulnificus & Crab shell & $\begin{array}{l}\text { Topical: } \\
\text { Gentamycin }(9.1 \mathrm{mg} / \mathrm{mL}) \\
\text { Bacitracin }(10,000 \mathrm{U} / \mathrm{mL}) \\
\text { Tetracycline }(1 \%) \\
\text { Tobrmycin }(0.3 \%) \\
\text { Subonjunctival: } \\
\text { Gentamycin } 20 \mathrm{mg} \\
\text { Surgical debridement (day } 14)\end{array}$ \\
\hline 3 & Massey et al. [19] 2000 & V. vulnificus & Shucking oyster & 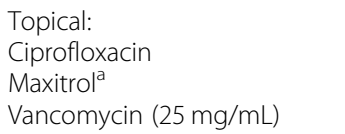 \\
\hline 4 & Penland et al. [2] 2000 & V. vulnificus & Shucking oyster & $\begin{array}{l}\text { Topical: } \\
\text { Cefazolin (5\%) } \\
\text { Gentamicin (1.4\%) } \\
\text { Prednisolone acetate (1\%) } \\
\text { Ciprofloxacin }(0.3 \%)\end{array}$ \\
\hline 5 & You et al. [20] 2008 & V. vulnificus & Wood of boat & $\begin{array}{l}\text { Topical: } \\
\text { Gatifloxacin } \\
\text { Tobramycin } \\
\text { Subconjunctival injection } \\
\text { Tobramycin ( } 20 \mathrm{mg}) \\
\text { Oral: } \\
\text { Doxycycline (100 mg/tab) bid } \\
\text { Systemic IV: } \\
\text { Ceftazidime ( } 2 \mathrm{~g}) \mathrm{q} 12 \mathrm{~h} \\
\text { Surgical debridement (day } 11 \text { ) }\end{array}$ \\
\hline 6 & Chen et al. 2019 & V. cholerae non-O1 & shrimp & $\begin{array}{l}\text { Topical: } \\
\text { Levofloxacin }(0.5 \%) \\
\text { Amikacin }(12.5 \mathrm{mg} / \mathrm{mL})\end{array}$ \\
\hline
\end{tabular}


cholerae non-O1 infection are scant and rudimentary. Our patient with normal immunity completely recovered under topical antibiotic therapy of fluoroquinolone and amikacin. This can be an effective topical regimen for treating $V$. cholerae non-O1 keratitis.

$V$. cholerae non-O1 can cause keratitis after ocular blunt injury by marine creatures and contaminated seawater. A satisfactory outcome can be achieved by comprehensive history taking, early pathogenic diagnosis and compatible antibiotic treatment.

\section{Abbreviations}

API 20E: Analytical Profile Index 20E; CT: Cholera toxin; PCR: Polymerase chain reaction; RXT: Repeats in toxin; T6SS: Type VI secretion system;

TBCS: Thiosulfate-citrate-bile salts-sucrose; TCP: Toxin-coregulated pilus

\section{Acknowledgements}

Not applicable.

\section{Authors' contributions}

WDC drafted the manuscript, LJL critical reviewed the manuscript, WHH participated the design of molecular study, TYH revised the manuscript and approved final submission. All authors have read and approved the final version of this manuscript.

\section{Funding}

The design of the study and the manuscript were supported by the grant (CMRPG6D0362) from Chang Gung Memorial Hospital. The microbial detection and laboratory analysis of the pathogen were supported by the grant (CORPG6E0051) from Chang Gung Memorial Hospital.

\section{Availability of data and materials}

All data generated or analyzed during this study are included in this published article.

\section{Ethics approval and consent to participate}

Ethics approval was obtained from Chang Gung Foundation.

\section{Consent for publication}

The patient's consent for publication was obtained.

\section{Competing interests}

The authors declare that they have no competing interests.

\section{Author details}

'Department of Ophthalmology, Chang Gung Memorial Hospital, Chiayi, Taiwan. ${ }^{2}$ Department of Chinese Medicine, School of Medicine, Chang Gung University, Taoyuan, Taiwan. ${ }^{3}$ Department of Orthopedics, Chang Gung Memorial Hospital, Chiayi, Taiwan. ${ }^{4}$ Division of Infectious Diseases, Department of Internal Medicine, Chang Gung Memorial Hospital, Chiayi, Taiwan. ${ }^{5}$ Graduate Institute of Clinical Medical Sciences, College of Medicine, Chang Gung University, Taoyuan, Taiwan.

Received: 31 January 2018 Accepted: 13 September 2019

Published online: 29 October 2019

\section{References}

1. Nicholas A, Daniels M, Shafaie A. A review of pathogenic Vibrio infections for clinicians. Infect Med. 2000;17(10):665-85.

2. Penland RL, Boniuk M, Wilhelmus KR. Vibrio ocular infections on the U.S. Gulf Coast. Cornea. 2000;19(1):26-9.

3. Johnson CN, Bowers JC, Griffitt KJ, Molina V, Clostio RW, Pei S, Laws E, Paranjpye RN, Strom MS, Chen A, et al. Ecology of Vibrio parahaemolyticus and Vibrio vulnificus in the coastal and estuarine waters of Louisiana, Maryland, Mississippi, and Washington (United States). Appl Environ Microbiol. 2012;78(20):7249-57.

4. Chen YT, Tang HJ, Chao CM, Lai CC. Clinical manifestations of non-O1 Vibrio cholerae infections. PLoS One. 2015;10(1):e0116904.
5. Chowdhury G, Joshi S, Bhattacharya S, Sekar U, Birajdar B, Bhattacharyya A, Shinoda S, Ramamurthy T. Extraintestinal infections caused by non-toxigenic Vibrio cholerae non-01/non-0139. Front Microbiol. 2016;7:144.

6. Yang CC, Lee BJ, Yang SS, Lin YH, Lee YL. A case of non-O1 and non-O139 Vibrio cholerae septicemia with endophthalmitis in a cirrhotic patient. Jpn J Infect Dis. 2008;61(6):475-6.

7. Ceccarelli D, Chen A, Hasan NA, Rashed SM, Huq A, Colwell RR. Non-O1/ non-0139 Vibrio cholerae carrying multiple virulence factors and $\mathrm{V}$. cholerae 01 in the Chesapeake Bay, Maryland. Appl Environ Microbiol. 2015;81(6): 1909-18.

8. Chatterjee S, Ghosh K, Raychoudhuri A, Chowdhury G, Bhattacharya MK, Mukhopadhyay AK, Ramamurthy T, Bhattacharya SK, Klose KE, Nandy RK. Incidence, virulence factors, and clonality among clinical strains of non-O1, non-O139 Vibrio cholerae isolates from hospitalized diarrheal patients in Kolkata, India. J Clin Microbiol. 2009:47(4):1087-95.

9. Figueroa-Arredondo P, Heuser JE, Akopyants NS, Morisaki JH, Giono-Cerezo $\mathrm{S}$, Enriquez-Rincon F, Berg DE. Cell vacuolation caused by Vibrio cholerae hemolysin. Infect Immun. 2001;69(3):1613-24.

10. Yi X, Wang Y, Yu FS. Corneal epithelial tight junctions and their response to lipopolysaccharide challenge. Invest Ophthalmol Vis Sci. 2000;41(13):4093100.

11. Wu Z, Nybom P, Magnusson KE. Distinct effects of Vibrio cholerae haemagglutinin/protease on the structure and localization of the tight junction-associated proteins occludin and ZO-1. Cell Microbiol. 2000;2(1):117.

12. Lin W, Fullner KJ, Clayton R, Sexton JA, Rogers MB, Calia KE, Calderwood SB, Fraser C, Mekalanos JJ. Identification of a vibrio cholerae RTX toxin gene cluster that is tightly linked to the cholera toxin prophage. Proc Natl Acad Sci U S A. 1999;96(3):1071-6.

13. Pukatzki S, Ma AT, Revel AT, Sturtevant D, Mekalanos JJ. Type VI secretion system translocates a phage tail spike-like protein into target cells where it cross-links actin. Proc Natl Acad Sci U S A. 2007;104(39):15508-13.

14. Sana TG, Baumann C, Merdes A, Soscia C, Rattei T, Hachani A, Jones C, Bennett KL, Filloux A, Superti-Furga G, et al. Internalization of Pseudomonas aeruginosa Strain PAO1 into Epithelial Cells is Promoted by Interaction of a T6SS Effector with the Microtubule Network. MBio. 2015;6(3):e00712.

15. Overman TL, Kessler JF, Seabolt JP. Comparison of API 20E, API rapid E, and API rapid NFT for identification of members of the family Vibrionaceae. J Clin Microbiol. 1985;22(5):778-81.

16. Baron S, Chevalier S, Lesne J. Vibrio cholerae in the environment: a simple method for reliable identification of the species. J Health Popul Nutr. 2007; 25(3):312-8

17. Panicker G, Call DR, Krug MJ, Bej AK. Detection of pathogenic Vibrio spp. in shellfish by using multiplex PCR and DNA microarrays. Appl Environ Microbiol. 2004;70(12):7436-44.

18. DiGaetano M, Ball SF, Straus JG. Vibrio vulnificus corneal ulcer. Case reports. Arch Ophthal. 1989;107(3):323-4.

19. Massey EL, Weston BC. Vibrio vulnificus corneal ulcer: rapid resolution of a virulent pathogen. Cornea. 2000;19(1):108-9.

20. You IC, Ahn M, Yoon KW, Yoon KC. A case of Vibrio vulnificus keratitis. Jpn J Ophthalmol. 2008;52(2):131-3.

\section{Publisher's Note}

Springer Nature remains neutral with regard to jurisdictional claims in published maps and institutional affiliations.

\section{Ready to submit your research? Choose BMC and benefit from:}

- fast, convenient online submission

- thorough peer review by experienced researchers in your field

- rapid publication on acceptance

- support for research data, including large and complex data types

- gold Open Access which fosters wider collaboration and increased citations

- maximum visibility for your research: over $100 \mathrm{M}$ website views per year

At BMC, research is always in progress.

Learn more biomedcentral.com/submissions 